\title{
UNEXPECTED SECOND ARTERIAL INJURY IN THE LOWER LIMB
}

\author{
C. G. MORAN, D. N. KREIBICH
}

Multiple arterial injuries associated with blunt trauma of the extremities are difficult to manage. Successful treatment depends upon early diagnosis and prompt revascularisation. We report a case where a second arterial injury in the same limb remained undetected, leading to delay in revascularisation.

Case report. A 20-year-old motorcyclist was admitted with multiple injuries following a road traffic accident. Clinical and radiological examination revealed a closed comminuted fracture of the mid-shaft of the femur, distal to which the circulation was absent. A minimally displaced, transverse fracture of the right medial malleolus was also noted.

Immediate manipulation failed to restore limb perfusion and exploration demonstrated a $1 \mathrm{~cm}$ patch laceration, with intimal tear, of the superficial femoral artery. The femoral fracture was stabilised with an intramedullary nail and then the artery repaired with a reversed saphenous vein graft. Despite good function of this graft there was no improvement in perfusion of the foot. A Fogarty catheter was passed distally but no thrombus was present and perfusion failed to improve. An open, four compartment decompression of the leg was performed via an anteromedial incision. There was free arterial bleeding from the lower end of the wound and exploration of this revealed complete rupture of the posterior tibial artery at the level of the undisplaced medial malleolar fracture. The artery was repaired with a reversed saphenous vein graft with some improvement in foot perfusion and, finally, the medial malleolar fracture was stabilised with a cancellous screw.

Unfortunately, 12 hours later the foot was obviously non-viable and a below-knee amputation was performed. The patient has since made an uneventful recovery.

Discussion. Arterial injuries following blunt trauma of the extremities are infrequent and usually result from road traffic accidents. Thus, they are often complicated by severe, local soft tissue damage and multiple system

C. G. Moran, FRCS (Ed), Orthopaedic Registrar

D. N. Kreibich, MB, BS, Orthopaedic Registrar

Department of Orthopaedics, Newcastle General Hospital, Newcastle upon Tyne NE4 6BE, England.

Correspondence to Mr C. G. Moran, Department of Orthopaedic Surgery, Sunderland General Hospital, Sunderland SR4 7TP, England.

(C) 1989 British Editorial Society of Bone and Joint Surgery

$0301-620 \mathrm{X} / 89 / 4 \mathrm{R} 12 \$ 2.00$

J Bone Joint Surg [Br] 1989:71-B:704. trauma. Their prognosis is worse than an isolated penetrating arterial injury at a similar site (Perry, Thal and Shires 1971).

Major arterial damage in the lower limb is usually associated with long bone fractures or dislocation of the knee. In such cases, soft tissue and bone injuries commonly occur at multiple levels. It is, however, unusual to see significant arterial damage at more than one site. Ransom et al (1981) reported a series of 58 patients of whom only two had suffered damage to more than one artery of the lower limb. The outcome in these two patients is not discussed but 14 of 36 patients $(39 \%)$ with blunt arterial injuries of the leg eventually required amputation.

In the case we report, a second ipsilateral arterial injury was not suspected until the femoral artery had been reconstructed. Despite a good anastamosis the runoff was poor and the limb remained pulseless. The second injury, to the posterior tibial artery, was associated with a fracture of the medial malleolus. There was minimal haematoma at this site as the blood flow had been interrupted by the proximal arterial injury and thus clinical diagnosis was impossible.

Limb salvage following blunt arterial injury of the extremities depends upon early diagnosis, prompt revascularisation and complete compartment decompression. If distal perfusion is poor following repair of an arterial injury then intra-operative arteriography should be performed immediately. This may reveal unexpected technical problems (Plecha and Pories 1972) and may also delineate distal arterial damage or thrombosis. The possibility of a second arterial injury should be considered and all fractures, however minor, are potential sites for this to occur.

We would like to thank Mr I. M. Pinder and Mr D. D. Milne for their kind permission to report this case.

No benefits in any form have been received or will be received from a commercial party related directly or indirectly to the subject of this article.

\section{REFERENCES}

Perry MO, Thal ER, Shires GT. Management of arterial injuries. Ann Surg 1971;173:403-8.

Plecha FR, Pories WJ. Intraoperative angiography in the immediate assessment of arterial reconstruction. Arch Surg 1972;105:902-7.

Ransom KJ, Shatney CH, Soderstrom CA, Cowley RA. Management of arterial injuries in blunt trauma of the extremity. Surg Gynecol Obstet 1981;153:241-6. 